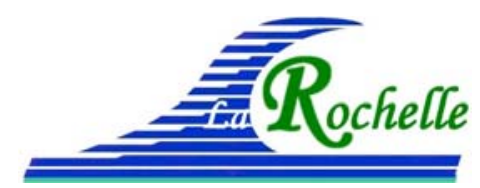

XVèmes Journées Nationales Génie Côtier - Génie Civil

La Rochelle, 29 au 31 mai 2018

DOI:10.5150/jngcgc.2018.023

(C) Editions Paralia CFL

disponible en ligne - http://www.paralia.fr - available online

\title{
Passive acoustic measurement and modelling of sandy bedload
}

\section{Olivier BLANPAIN ${ }^{1}$, Xavier DEMOULIN ${ }^{2}$, Thierry GARLAN ${ }^{1}$}

1. Service Hydrographique et Océanographique de la Marine, équipe sédimentologie, 13, rue du Chatellier, CS92803, 29228 Brest Cedex 2. blanpain@shom.fr 2. MAREE, 15 rue Galilée - 56270 Ploemeur.xdemoulin@maree.fr

\begin{abstract}
:
Bedload transport monitoring at sea still remains a challenge for sedimentologists and coastal engineers. Indeed, data and instrumental techniques that establish a detailed link between boundary layer turbulence and sediment mixture dynamics are scarce.

The passive acoustic method, based on hydrophones measuring self-generated noise due to inter-particle collisions, has been mostly developed in laboratories on coarse particles during the past decades. It has been shown that the amplitude and the frequency spectrum of the monitored signals are linked to bedload fluxes and grain size distribution. This technique shows numerous advantages: it is not disruptive to the flow field, easy to handle and cost effective.

One experiment at sea is reported here. It was conducted on a sandy dune subject to strong tidal currents. Hydrodynamic parameters near the bed have been provided by Doppler velocimeters. Signal processing was adapted to distinguish the useful information, bedload self-generated noise, from other sound sources. Passive acoustic data proved to fit well with the intensity of bedload transport.

Since the measured signal generated by particle collisions has been discriminated confidently, an empirical model is proposed to generate a simulated signal as a summation of individual shock signals. The latter is mainly affected by moving particle number and size. Thus, by minimizing the error between acoustic intensity simulated and measured, the optimized grain sizes can be calculated.

The validity of this inversion process depends on the empirical model precision. Data acquired in a controlled environment are now needed to better take into account the different processes involved to generate the simulated signal.
\end{abstract}

\section{Keywords:}

Bedload, sand, acoustic, self-generated noise. 


\section{Thème 2 - Dynamique sédimentaire}

\section{Introduction}

Bedload transport monitoring at sea still remains a challenge for sedimentologists and coastal engineers. Although such measurements are required to validate sediment transport models, data and instrumental techniques that establish a detailed link between boundary layer turbulence and sediment mixture dynamics are still scarce. Passive acoustic devices can offer this possibility when associated with high-frequency velocity measurements near the bed. The method is based on the use of hydrophones recording self-generated noise due to inter-particle collisions during bedload transport. It presents numerous advantages: it is not disruptive to the flow field or the seabed, light, easy to handle and cost effective.

The literature mainly describes developments made in controlled conditions with coarse particles (THORNE, 1985; THORNE, 1986). A few experiments were conducted in rivers (BELLEUDY et al, 2010; GEAY, 2013) or in the marine environment (THORNE, 1986). It has been shown that the amplitude and the frequency spectrum of the monitored signals are linked to bedload fluxes and grain size distribution. From laboratory studies, it has been shown that the observations could be explained in terms of rigid body radiation, which arises from the sudden velocity change of the impacting particles (THORNE \& FODEN, 1988).

The present paper describes further developments in the prediction of the global selfgenerated noise level emitted by natural sand grains subject to tidal currents. Measurements on a sandy dune in the Iroise Sea (France) are first briefly described and then an empirical model is proposed to generate a simulated signal as a summation of individual shock signals. Its intensity is mainly affected by the number of moving particles and their sizes. Thus, by minimizing the error between acoustic levels simulated and measured, the optimized grain size or the sediment fluxes can be calculated.

\section{Methodology}

\subsection{In-situ measurements}

The study area is located in the Four Channel of the Iroise Sea at a depth of 60 meters. The sea floor is covered by sandy dunes and influenced by strong tidal currents up to 1 $\mathrm{m} / \mathrm{s}$. An instrumented frame was deployed on the sea bottom during 3 days of smooth to moderate sea conditions.

Passive acoustic data were acquired with the use of one hydrophone located $40 \mathrm{~cm}$ above the bottom. Current velocity was recorded with an upward-looking ADCP. No grab sediment samples were collected during the deployment. But data acquired during previous surveys in the area provide the specification of the seabed sediments: the median grain-size diameter ranges from $0.4 \mathrm{~mm}$ to $1 \mathrm{~mm}$. 


\section{XVèmes Journées Nationales Génie Côtier - Génie Civil \\ La Rochelle, 29 au 31 mai 2018}

Acoustic data and current velocities were recorded during fifteen minutes every half an hour. In order to reduce the background noise, the raw acoustic signal was high-pass filtered with a $10 \mathrm{kHz}$ cutoff frequency. The filtered signal is composed of short spikes $(0,05 \mathrm{~ms}$ typical duration, $100 \mathrm{kHz}$ dominant frequency) emerging from the background sound. Thus, the temporal signal can be considered as a combination of successive and numerous shocks due to sediment transport. A root mean square (rms) pressure was calculated every minute. This Prms is associated with a velocity measurement at the same time.

\subsection{Model description}

The model aims to estimate the total rms pressure generated by moving sand particles on the sea floor. In accordance with the observations, the temporal simulated signal is considered to be the combination of individual shock signals. Figure 1 presents a diagram of the modeling strategy we used and highlights the different processes we need to quantify.

For each current velocity $\mathrm{u}$ and grain size D, we first calculate the number of moving grains $\mathrm{N}$ and their velocity during the collision Uc. Then, the number of impacts $\mathrm{NbC}$ and the pressure radiated from a pair of impacting particles Pp are quantified. Finally, a total rms pressure level Prms is obtained by the summation of each particle impact signal.

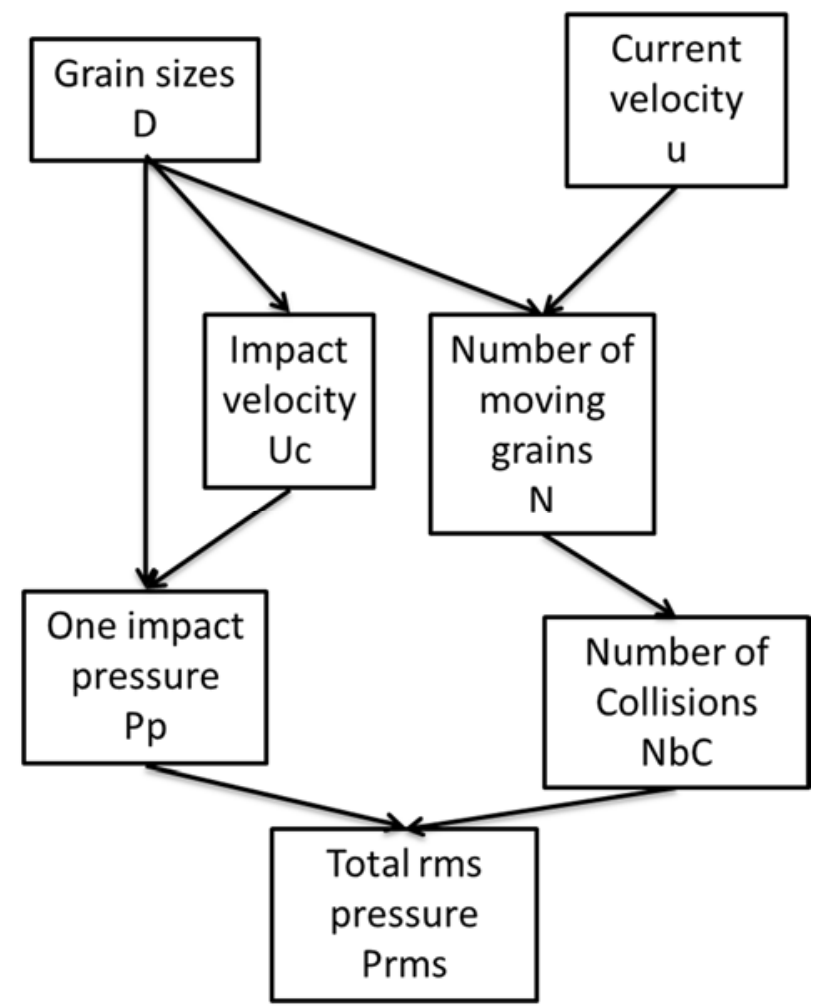

Figure 1. Diagram of the modelling strategy. 


\section{Thème 2 - Dynamique sédimentaire}

\subsubsection{Collision number estimation}

The Shields diagram (SHIELDS, 1936; SOULSBY, 1997) is widely used to specify the critical thresholds for initiation of sand grain motion. Thus, for each current velocity and grain-size value, the mobility parameter can be calculated and compared to the critical threshold for initiation of motion to determine if particles are moving.

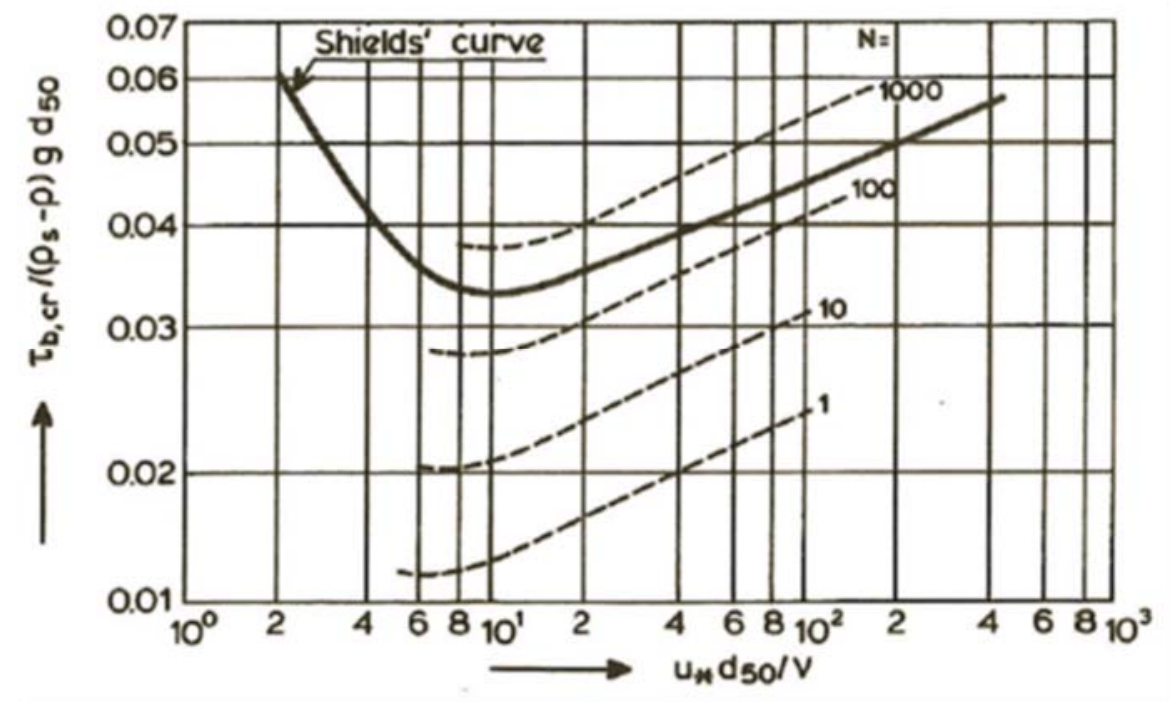

Figure 2. Number of particles moving per unit area $\left(\mathrm{m}^{2}\right)$.

VAN RIJN (1993) plotted the Shields curve on a diagram with the aim of quantifying the number of sand grains moving per unit area (figure 2).

It is noticeable that the Shields curve is included between the 100 and the 1000 moving particle curves. This seems to indicate that the Shields criterion corresponds to a global initiation of motion or to a permanent particle movement and not a single grain movement at one location.

Figure 2 allows us to evaluate the number of moving grains per unit area as a function of particle diameter and current speed. During the measurement campaign, the Shields criterion corresponded to $\mathrm{N}=300$ moving particles. By fitting the number of moving particles versus the ratio between the mobility number for $\mathrm{N}$ particles, and the Shields criterion, we obtain the following expression:

$$
\mathrm{N}=10^{5.33-2.78 \cdot{ }^{\mathrm{u}_{*, \mathrm{cr}}^{2}} / \mathrm{u}_{*, \mathrm{~N}}^{2}}
$$

The number of collisions $N b C$ between a moving particle and grains on the sea floor is estimated as:

$$
N b C=N \cdot S \cdot P
$$




\section{XVèmes Journées Nationales Génie Côtier - Génie Civil \\ La Rochelle, 29 au 31 mai 2018}

with $S$ the surface of sea floor where impacts contribute to the signal level recorded by the hydrophone (figure 3 ) and $P$ the probability of collision for each moving grain. According to THORNE (1986):

$$
P=10 \% \text {. }
$$

The distance $a$ corresponds to the radius of the surface $S$. Assuming each impact of a pair of grains is considered as a dipolar source, $a$ is estimated as twice the distance $h$ between hydrophone and sea floor (DEMOULIN, 2013) and thus:

$$
S=4 \cdot \Pi \cdot h^{2}
$$

Thus, during data acquisition, $S$ is $2 \mathrm{~m}^{2}$.

Each particle collision is thus associated with an angle $\theta$ and a distance $r$ to the hydrophone.

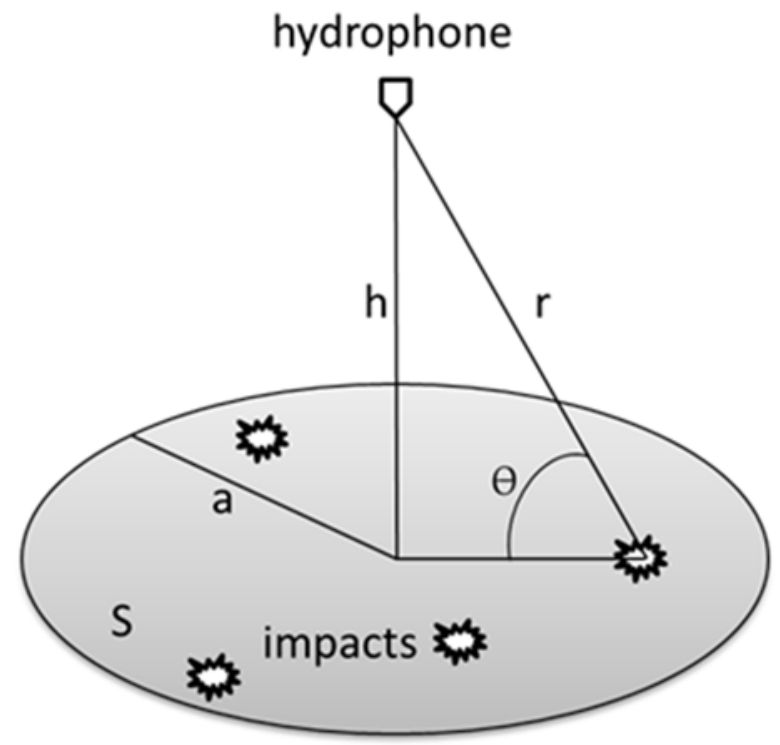

Figure 3: Geometry for the signal generation modeling.

\subsubsection{Pressure radiated from a pair of impacting grains}

THORNE \& FODEN (1988) described a theoretical framework for the generation of underwater sound by colliding spheres. Rigid-body radiation theory has been adopted. The solution proposed considers that each sphere is an independent source that generates a transient that can be described by an impulse solution convolved with the acceleration time history during the collision. The impact process is assumed to be elastic so that a Hertzian acceleration description can be employed. The sound field is then obtained from the sum of the two signals. Thus, the total pressure radiated from a pair of impacting grains is formed by the contribution of each particle. The set of equations can be simplified if: (i) the particles are the same (equivalent diameter and mass), (ii) their density is larger than half the water density and, (iii) the range distance $r$ 


\section{Thème 2 - Dynamique sédimentaire}

is larger than the particle radius. The impact velocity is considered equal to the current velocity at height $\mathrm{D}$ above the seabed.

\subsubsection{Total rms pressure generation}

The total pressure generated, Prms, is the summation of pressure signals $P_{p}$ radiated by each collision for each particle randomly scattered on the sea floor surface $S$ during an integration time $T$ split in $x$ periods.

$$
P_{r m s}=\sqrt{\frac{1}{x} \sum_{i=1}^{x} \sum_{N b C} \sum_{D} P_{p}(i)^{2}}
$$

\section{Results}

Following the modeling strategy, the particle size is optimized by minimizing the error between acoustic pressure simulated and measured. A rms pressure is calculated for particle sizes varying from $\mathrm{D}=0.1 \mathrm{~mm}$ to $\mathrm{D}=2 \mathrm{~mm}$ by step of $0.1 \mathrm{~mm}$. The root mean square deviation is minimized for particle size of $0.8 \mathrm{~mm}$. This value is equivalent to the median diameter of sediment samples previously realized near the deployment site. The match with the measurements is shown on figure 4 . The model tends to underestimate measured Prms and especially fails to reproduce the higher values that are recorded when current velocities are important (more than $0.75 \mathrm{~m} . \mathrm{s}^{-1}$ ). Under these strong hydrodynamic conditions, an important spreading of Prms is noticeable for a same current speed value. This observation can be due to (i) the turbulent bursting phenomenon of sediment transport, or (ii) the grains hitting the instrument frame. In either case, the model is not set up to simulate these processes.

Another model limitation can explain the underestimation of pressure: only impacts between two particles of the same diameter are taken into account. However, we can consider than the probability for a moving grain to impact a non-moving coarser one is higher, and then the induced pressure is higher.

These results are obtained for a single size diameter representative of well sorted sediment. The measured curve has been manually fitted by four red straight lines delimiting four sections ( 1 to 4 in figure 4). This partitioning can be explained by the contribution of bigger grains set into motion with the increase of current velocity. A better error minimization should be reached by taking into account a grain size distribution 


\section{XVèmes Journées Nationales Génie Côtier - Génie Civil \\ La Rochelle, 29 au 31 mai 2018}
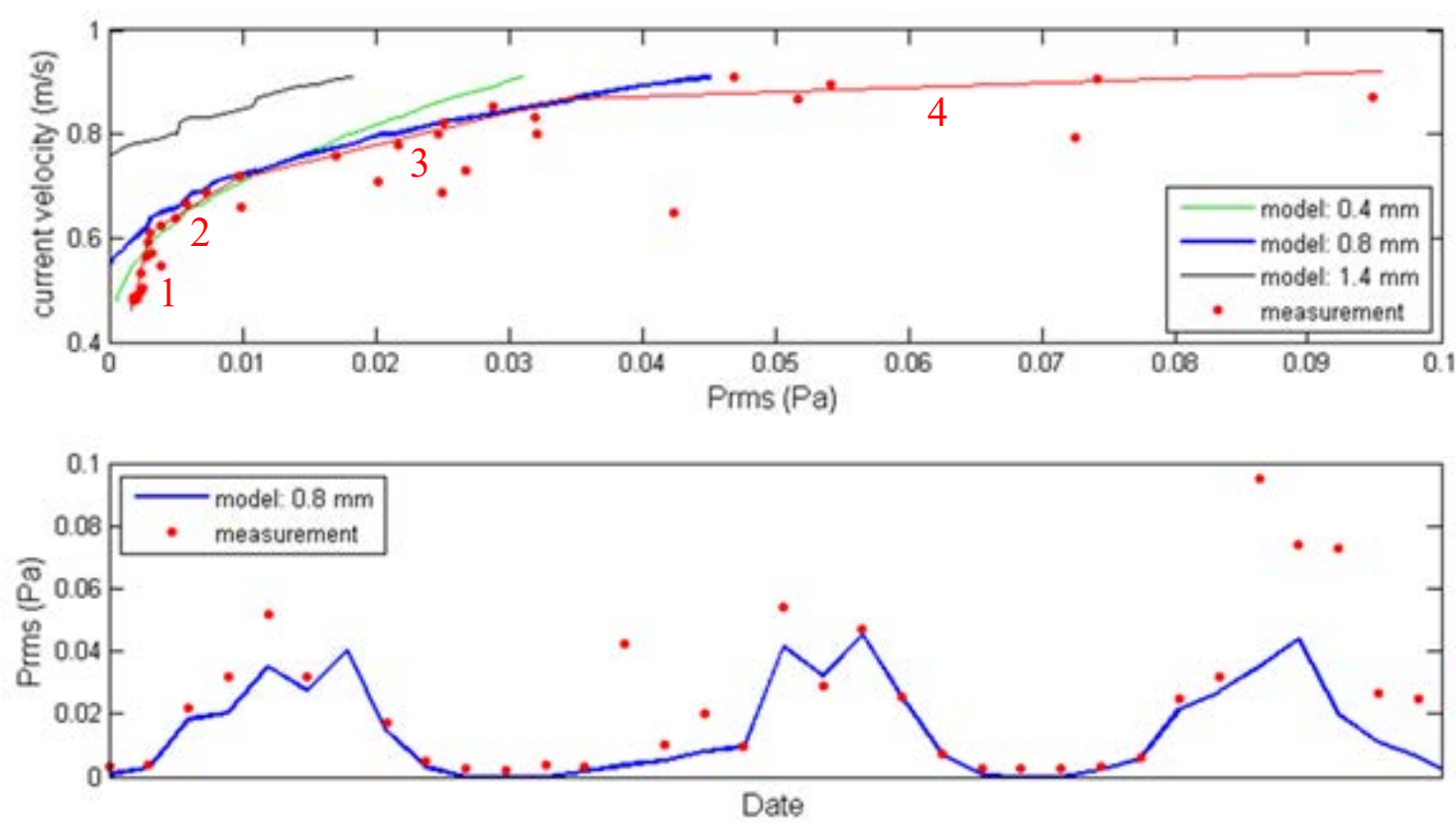

Figure 4: Comparison between model calculation and measurements.

\section{Conclusion}

A sea experiment has been undertaken to evaluate the feasibility of using passive acoustics for sand transport characterization. Measurements have shown that the recorded Prms evolves with current velocity fluctuations and, even for grain sizes as small as sand, self-generated noise due to inter-particle collisions can be relevant to identify bedload transport.

An empirical model has been set up in order to simulate the pressure signal due to moving grains. Governing parameters are the number of moving particles and their size. By fitting the pressure measured and calculated, a median grain size involved in the sediment transport has been evaluated. This value is consistent with the medium grain size observed in the area. Preliminary attempts made with several grain sizes tend to improve the simulated signal.

The validity of this inversion process depends on the model precision and the raw data processing. Major limitations can be overcome by taking into account collision from two particles of different size. Data acquisition can be improved by using a hydrophone with a higher frequency sampling rate and a lower signal-to-noise ratio. A signal analysis effort can be made on the detection of grain-frame impacts.

\section{References}

BELLEUDY P., VALETTE A., GRAFF B. (2010). Passive Hydrophone Monitoring of Bedload in River Beds: First Trials of Signal Spectral Analyses. U.S. Geological Survey Scientific Investigations, Report 2010-5091, pp 266-282. 


\section{Thème 2 - Dynamique sédimentaire}

BUFINGTON J. M., MONTGOMERY D. R. (1997). A systematic analysis of eight decades of incipient motion studies, with special reference to gravel-bedded rivers. Water Resources Research, Vol. 33, pp 1993-2029. https://doi.org/10.1029/96WR03190 DEMOULIN X. (2013). Vagues, bulles et sons. Rapport MAREE.

GEAY T. (2013). Mesure acoustique passive du transport par charriage dans les rivières. Thèse de doctorat de l'Université de Grenoble, 163 p.

SHIELDS A. (1936). Application of similarity principles and turbulence research to bedload movement. Hydrodynamics Laboratory, California Institute of Technology.

SOULSBY R. (1997). Dynamics of marine sands. Thomas Telford Publication.

THORNE P.D. (1985). The measurement of acoustic noise generated by moving artificial sediments. The Journal of the Acoustical Society of America, Vol. 78, pp 1013-1023. https://doi.org/10.1121/1.393018

THORNE P.D. (1986). Laboratory and marine measurements on the acoustic detection of sediment transport. The Journal of the Acoustical Society of America, Vol. 80, pp 899-910. https://doi.org/10.1121/1.393913

THORNE P.D., FODEN D.J. (1988). Generation of underwater sound by colliding spheres. The Journal of the Acoustical Society of America, Vol. 84, pp 2144-2152. https://doi.org/10.1121/1.397060

VAN RIJN L. (1993). Principles of sediment transport in rivers, estuaries and coastal seas. Part 1, Aqua Publications. 